\title{
O empreendedorismo de negócios entre enfermeiros
}

\author{
Business entrepreneurship among nurses \\ El emprendimiento de negocios entre enfermeros
}

\author{
Sabrina de Cássia Chagas'; Priscila Néria Milagres"; Mariana Cristina Rodrigues Silvall'; \\ Ricardo Bezerra Cavalcanteiv; Patrícia Peres de Oliveirav ; Regina Consolação dos Santos ${ }^{v /}$.
}

\begin{abstract}
RESUMO
Objetivo: caracterizar o empreendedorismo de negócios entre enfermeiros. Método: estudo de caso com abordagem quantitativa, apoiado nos conceitos de Schumpeter. Os dados foram coletados em um município mineiro, em 2015, por meio da aplicação de um questionário validado e entrevistas semiestruturadas com 10 enfermeiros empreendedores. 0 tratamento dos dados foi realizado por meio da análise de conteúdo, modalidade temático-categorial e os dados relacionados ao perfil e características comportamentais com auxílio do software STATA versão 12.0. Aprovado por Comitê de Ética em Pesquisa. Resultados: verificou-se que a maioria dos enfermeiros possuem empreendimentos registrados, de alta lucratividade e voltados para a assistência domiciliar. As características comportamentais: busca de informações, planejamento e monitoramento sistemático e persuasão e rede de contatos precisam ser potencializadas. Conclusão: o empreendedorismo de negócios entre os enfermeiros estudados conformou-se como uma oportunidade profissional vislumbrada a partir da necessidade de lucratividade e satisfação pessoal, o que os obrigou a deslocarem-se dos nichos tradicionais de trabalho.

Descritores: Mercado de trabalho; prática empresarial; enfermagem; empreendedorismo.
\end{abstract}

\section{ABSTRACT}

Objective: tto characterize business entrepreneurship among nurses. Method: in this quantitative case study, framed conceptually by Schumpeter, data were collected in 2015 , by validated questionnaire and semi-structured interview, from ten business entrepreneur nurses in a municipality in Minas Gerais. The data were analyzed by thematic category content analysis, while data on profile and behavioral characteristics were analyzed using STATA (version 12.0). The study was approved by the research ethics committee. Results: most of the nurses were found to have highly profitable registered businesses providing home care. The following behavioral characteristics need to be leveraged: information search, planning and systematic monitoring, and contact persuasion and network. Conclusion: business entrepreneurship among the nurses studied constituted a professional opportunity envisaged in response to the need for profit and personal satisfaction, which forced them to move away from their traditional professional niches.

Descriptors: Labor market; business practice; nursing; entrepreneurship.

\section{RESUMEN}

Objetivo: caracterizar el emprendimiento de negocios entre enfermeros. Método: estudio de caso con enfoque cuantitativo, apoyado en los conceptos de Schumpeter. Los datos fueron recolectados en un municipio de Minas Gerais, en 2015, por medio de la aplicación de un cuestionario validado y entrevistas semiestructuradas junto a diez enfermeros emprendedores. El análisis de los datos fue realizado por medio del análisis de contenido, modalidad temático-categorial y los datos relacionados al perfil y características conductuales utilizando el software STATA versión 12.0. Aprobado por el Comité de Ética en Investigación. Resultados: se verificó que la mayoría de los enfermeros poseen emprendimientos registrados, de alta rentabilidad y volcados a la atención domiciliaria. Las características conductuales: búsqueda de información, planificación y monitoreo sistemático y persuasión y red de contactos necesitan ser potenciadas. Conclusión: el emprendimiento de negocios entre los enfermeros estudiados se conformó como una oportunidad profesional vislumbrada a partir de la necesidad de rentabilidad y satisfacción personal, lo que los obligó a desplazarse de los nichos tradicionales de trabajo.

Descriptores: Mercado de trabajo; práctica empresarial; enfermería; emprendedorismo.

\section{INTRODUÇÃO}

O empreendedorismo de negócios na enfermagem tem proporcionado à disponibilização de serviços que envolvem a prestação de cuidados, educação e administração ${ }^{1}$. Neste contexto, o enfermeiro empreendedor é aquele que trabalha com ideias e oportunidades econômicas, reúne capital e recursos para produção de serviços e bens. Essa definição se equipara ao conceito desenvolvido por Schumpeter, um dos primeiros autores a conceituar o ser empreendedor, como aquele que produz novas ideias e consegue programar o novo ${ }^{2,3}$.

'Enfermeira. Universidade Federal de São João del Rei. Minas Gerais, Brasil. E-mail: sabrinachagas1@hotmail.com.

"Enfermeira. Universidade Federal de São João del Rei. Minas Gerais, Brasil. E-mail: milagresp@ hotmail.com.

"Enfermeira. Universidade Federal de São João del Rei. Minas Gerais, Brasil. E-mail: maryrodrigues235@hotmail.com.

IVEnfermeiro. Professor de Metodologia Científica da Universidade Federal de São João Del-Rei. Minas Gerais, Brasil.E-mail ricardocavalcante@ufsj.edu.br.

vEnfermeira. Professora Adjunta da Universidade Federal de São João Del-Rei. Minas Gerais, Brasil. E-mail: pperesoliveira@gmail.com.

v'Enfermeira. Mestre em Ciências. Docente na Universidade de Itaúna. Itaúna, Minas Gerais, Brasil. E-mail: reginasantos72@outlook.com. 
Estudos internacionais demonstram que enfermeiros buscam o empreendedorismo de negócios para escapar dos limites impostos pelas instituições tradicionais de saúde ${ }^{4-6}$. O enfermeiro, além de ter capacidade de compreender as necessidades humanas de forma integral, tem também potencial para explorar novas áreas, não precisando ater-se a um posto de trabalho tradicional em que prevalece a noção de doença. 0 enfermeiro ao identificar uma necessidade institui um serviço para suprir essa necessidade, e passa atuar como empreendedor de seu próprio negócio 7 .

No Brasil, ainda há poucos estudos que abordam o empreendedorismo de negócios na área da enfermagem, e estão mais focados no empreendedorismo social $^{8}$. Assim, justifica-se a necessidade de ampliar o conhecimento acerca do empreendedorismo de negócios entre enfermeiros, buscando conhecer as características das atividades empreendedoras e o perfil desses enfermeiros a fim de se entender suas potencialidades empreendedoras. Para tanto, este estudo teve como objetivo caracterizar o empreendedorismo de negócios entre enfermeiros.

\section{REFERENCIAL TEÓRICO}

Atualmente as transformações econômicas, tecnológicas e sociais vêm sendo discutidas por causarem impacto no mercado de trabalho. Observa-se também uma transição do modelo econômico, onde a busca por estabilidade no trabalho, passa a ser, no novo modelo, alcançar satisfação profissional, autonomia e segurança ${ }^{9}$.

Empreendedorismo pode ser considerado uma expressão derivada da tradução da palavra entrepreneurship, designado ao estudo referente ao empreendedor desde sua origem à sua atuação ${ }^{10}$. Um dos primeiros autores a conceituar o que é o empreendedor, o descreve como aquele que cria novos, e/ou renova processos tradicionais. Ainda complementa que o empreendedor é aquele que produz novas ideias e consegue programar o novo ${ }^{2}$.

O empreendedorismo estabelece uma ação através da concepção de novos produtos/processo e/ou da exploração de novas áreas. Assim, ser empreendedor significa tomar atitudes frente a uma oportunidade que vale a pena ser trabalhada ${ }^{11}$.

Atualmente, o empreendedorismo emerge em diversas áreas, inclusive da saúde, onde ele tem se destacado, como na enfermagem ${ }^{12}$. O enfermeiro tem naturalmente habilidades gerenciais sobre o processo saúde-doença, incluindo a capacidade de gerenciamento de recursos físicos, materiais, humanos e financei$\operatorname{ros}^{13}$. Contudo, o enfermeiro tem ampliado e inovado sua atuação profissional ao criar empreendimentos fundamentados nas necessidades e oportunidades do mercado de trabalho ${ }^{14}$.

\section{Metodologia}

Trata-se de estudo de caso único, que visa estudar um fenômeno específico e pouco conhecido ${ }^{15}$, com abordagem qualitativa, devido à necessidade de se captar as vivências dos participantes ${ }^{16}$, apoiado nos conceitos de Schumpeter ${ }^{2}$. Dessa forma, como o empreendedorismo de negócios é algo recente no contexto da enfermagem, um estudo de caso pode contribuir com detalhes e minúcias que ainda não foram descritos na literatura. A pesquisa obedeceu à Resolução $n$ ㅇ 466/2012 do Conselho Nacional de Saúde e foi aprovada pelo Comitê de Ética em Pesquisa com Seres Humanos da Universidade Federal de São João Del Rei sob parecer/ no076951/20.

O cenário definido para a realização do estudo foi um município mineiro, referência de saúde para 54 municípios em seu entorno, em 2015. A definição dos participantes do estudo ocorreu por meio da identificação dos enfermeiros que possuem empresas e/ou autônomos, dentro do contexto de saúde e/ou enfermagem.

Inicialmente foi identificado o primeiro enfermeiro empreendedor em destaque na mídia, congressos e no Conselho Regional de Enfermagem de Minas Gerais (COREN-MG) com atuação no município em estudo. Esse enfermeiro foi convidado a participar desta pesquisa e foi solicitado a ele a indicação de outros enfermeiros empreendedores, de acordo com os critérios anteriormente estabelecidos.

Foi utilizada a técnica Snowball, também conhecida como técnica da bola de neve, que é utilizada em pesquisas sociais. Ela é não probabilística, ou seja, os primeiros participantes indicam outros novos participantes e assim sucessivamente até que se atinja o ponto de saturação ${ }^{17}$. O ponto de saturação foi atingido ao total de 10 enfermeiros empreendedores entrevistados.

A coleta de dados foi realizada a partir da aplicação de um roteiro semiestruturado, composto por duas partes. A primeira que caracterizava o perfil do enfermeiro e de seu empreendimento e a segunda parte composta por questões abertas contendo as motivações, facilidades e dificuldades relacionadas com seu empreendimento. As entrevistas foram gravadas e posteriormente transcritas. Cada enfermeiro recebeu um código para garantir o anonimato (letra $\mathrm{E}=$ Enfermeiro e o número 1 a 10 para as entrevistas). As entrevistas tiveram uma duração média de 50 minutos e foram realizadas no local definido a priori pelo entrevistado. O período de coleta de dados ocorreu de julho a setembro de 2015.

Os dados provenientes das entrevistas foram submetidos à análise de conteúdo, modalidade temático-categorial ${ }^{18}$, por meio da pré-análise ou leitura flutuante e exploração e codificação do material que, ao final foram tratados de maneira a serem significantes 
e válidos. Também foram avaliadas as características comportamentais empreendedoras dos enfermeiros participantes do estudo, além de seu perfil. Para tanto, foi utilizado o questionário formulado por McClelland.

Composto por 55 afirmações, tal questionário tem por objetivo identificar as características comportamentais dos empreendedores (CCE, distribuídas em dez grupos: busca de oportunidades e iniciativa; persistência; comprometimento; exigência de qualidade e eficiência; correr riscos calculados; estabelecimento de metas; busca de informações; planejamento e monitoramento sistemático; persuasão e rede de contatos; independência e autoconfiança. O questionário propõe uma autoavaliação, em que devem ser pontuadas as respostas com notas de 1 a 5, que irá expressar o comportamento do entrevistado. Ao final do questionário, soma-se o resultado de cada afirmativa, que indicará a intensidade de cada um dos comportamentos empreendedores do entrevistado. A pontuação máxima é de 25 pontos para cada característica, sendo considerado empreendedor aquele que atinja pontuação mínima de 15 pontos. Ainda foi aplicado um fator de correção, cuja finalidade é corrigir uma eventual tendência do respondente de apresentar uma imagem altamente favorável de si mesmo ${ }^{19}$.

Os dados do questionário foram analisados com auxílio do software STATA versão 12.0. Realizou-se cálculo de medidas de tendência central (media e mediana) e de dispersão (desvio-padrão, valores mínimos e máximos) dos 10 grupos de características avaliados do questionário.

\section{RESULTADOS}

Em relação ao perfil dos enfermeiros entrevistados, $70 \%$ eram do sexo feminino, predominando a faixa etária entre 30 a 40 anos. Todos realizaram graduação em instituição privada. Notou-se que $40 \%$ dos enfermeiros possuem mais de uma especialização, entretanto estas nem sempre estão ligadas à sua área de atuação no empreendimento. Ressalta-se a alta lucratividade mensal desses empreendedores, que variou entre $\mathrm{R} \$$ $1.800,00$ a $\mathrm{R} \$ 85.000$, como evidenciado na Figura 1.

Do total de entrevistados, $50 \%$ exercem atualmente outra atividade além do seu empreendimento. Todos já trabalharam em outros locais antes de seus empreendimentos e $70 \%$ apresentam CNPJ e razão sociais devidamente registradas em órgão competente. Em relação às CCEs dos enfermeiros entrevistados, considerando o questionário proposto por McClelland e sua pontuação recomendada (15 a 25), nota-se que o comprometimento, estabelecimento de metas e independência e autoconfiança foram às características que obtiveram maiores médias. Já considerando as características com menores médias, destacam-se a persuasão e rede de contatos e a persistência. Entretanto, considerando a média, percebe-se que todas as características ultrapassaram o valor mínimo recomendado, conforme mostra Tabela 1.

Verificou-se também que os enfermeiros E6, E10 e E7, E9 apresentaram o valor mínimo nas CCEs busca de informações e persuasão e rede de contatos, respectivamente. Além disso, o E2 foi o único a não alcançar o valor

\begin{tabular}{|c|c|c|c|}
\hline Entrevistado & Especialização & Empreendimento & $\begin{array}{l}\text { Lucro líquido médio } \\
\text { mensal (R\$) }\end{array}$ \\
\hline \multirow{3}{*}{ E1 } & Urgência e Emergência & \multirow{3}{*}{ Home Care } & \multirow[t]{3}{*}{30.000} \\
\hline & Terapia intensiva & & \\
\hline & Saúde Pública & & \\
\hline E2 & Não possui especialização & Instituição de longa permanência & 9.000 \\
\hline E3 & Administração Hospitalar & & \\
\hline \multirow{3}{*}{ E4 } & Aleitamento Materno & Assistência à amamentação no domicílio & 12.000 \\
\hline & Saúde Pública & & \\
\hline & Auditoria e Sistemas de Saúde & $\begin{array}{l}\text { Assistência ao pré-natal, parto, puerpério e } \\
\text { puericultura em domicilio }\end{array}$ & 5.000 \\
\hline E5 & $\begin{array}{l}\text { Estomaterapia } \\
\text { Enfermagem Gerencial } \\
\text { Administração Hospitalar }\end{array}$ & $\begin{array}{l}\text { Cuidados com portadores de feridas crônicas } \\
\text { em domicílio }\end{array}$ & Não informado \\
\hline E6 & Obstetrícia & $\begin{array}{l}\text { Assistência ao pré-natal, parto, puerpério e } \\
\text { puericultura em domicilio }\end{array}$ & 1.800 \\
\hline E7 & Não possui especialização & Loja de materiais hospitalares & Não informado \\
\hline \multirow[t]{3}{*}{ E8 } & Estomaterapia & Home Care & \\
\hline & \multirow{2}{*}{ Urgência e Emergência } & Instituição de longa permanência & \multirow[t]{2}{*}{85.000} \\
\hline & & Loja de material hospitalar & \\
\hline E9 & Não possui especialização & Home Care & 8.000 \\
\hline E10 & Saúde Pública & Instituição de longa permanência & 30.000 \\
\hline
\end{tabular}

FIGURA 1: Caracterização dos enfermeiros estudados. Município de médio porte do Centro-Oeste Mineiro, julho a setembro de 2015. 
TABELA1: Caracterização dos Comportamentos Empreendedores dos enfermeiros estudados. Município de médio porte do Centro-Oeste Mineiro, Julho a setembro de 2015.

\begin{tabular}{|c|c|c|c|c|}
\hline CCEs & Média \pm desvio padrão & Mediana & Valor mínimo & Valor Máximo \\
\hline Busca de oportunidade e iniciativa & $18,50 \pm 0,54$ & 19 & 16 & 21 \\
\hline Persistência & $17,30 \pm 0,33$ & 17,5 & 16 & 19 \\
\hline Comprometimento & $21,50 \pm 0,68$ & 23 & 17 & 23 \\
\hline Exigência de qualidade & $18,80 \pm 0,66$ & 18,5 & 16 & 21 \\
\hline Correr riscos calculados & $19,90 \pm 0,72$ & 21 & 16 & 23 \\
\hline Estabelecimento de metas & $20,80 \pm 0,69$ & 20,5 & 18 & 25 \\
\hline Busca de informações & $18,40 \pm 0,83$ & 19 & 15 & 23 \\
\hline Planejamento e monitoramento sistemático & $16,90 \pm 0,76$ & 17 & 13 & 22 \\
\hline Persuasão e rede de contatos & $17,50 \pm 0,60$ & 17,5 & 15 & 21 \\
\hline Independência e autoconfiança & $20,50 \pm 0,76$ & 20 & 17 & 24 \\
\hline
\end{tabular}

mínimo preconizado pelo questionário, alcançando na CCE Planejamento e monitoramento sistemático valor de 13 pontos. Entretanto, no geral, nota-se que a grande maioria dos empreendedores alcançou a pontuação necessária para ser considerado empreendedor conforme McClelland, como expõe a Figura 2.

A gênese do empreendedorismo de negócios e empreendedorismo: dificuldades, satisfação e metas

A formação e motivações para o empreendedorismo foram reconhecidas pelos enfermeiros entrevistados. Primeiramente, destacou-se que o período da graduação pouco contribuiu para o despertamento ao empreendedorismo:

Muito pouco. Quase nada, na verdade. Eu senti muita falta disso [o empreendedorismo] na graduação. (E3)

Já outro entrevistado relata:

Acho que quase todas as faculdades que você vai ele te forma focado no profissional usual, técnico [...] Eu acho que nem é incompetência do curso, a grade ela é projetada para você ser um enfermeiro cuidador e não um empreendedor. (E1)

Os enfermeiros verbalizaram suas motivações para o processo de empreender em um negócio próprio.
Percebe-se que estavam relacionadas à possibilidade de lucratividade e a independência no negócio:

Acho que a independência de gestão, ter o que é meu sabe. Achei que eu poderia contribuir e que eu visualizei lucratividade nisso. (E1)

Além disso, alguns entrevistados citaram a facilidade na divulgação como um dos fatores contribuintes para o processo de empreender:

Uma facilidade de divulgar por a gente trabalhar na área, conhecer pessoas. (E4)

O apoio familiar, a experiência prévia e a demanda do mercado também foram referidas como principais facilitadores no processo de empreender.

Minha mãe sempre me apoiou em tudo em relação a ideia [...] em relação as facilidades, foi o seguinte: o paciente tinha, o público para você trabalhar tinha, então a oferta de trabalho sempre teve, então ajudava. (E1.

Além das facilidades para empreender, os participantes também destacaram as características pessoais e conhecimentos necessários para o empreendedorismo, compondo a terceira subcategoria. Reconheceu-se que para empreender são necessárias algumas características: desejar ser dono do próprio negócio, ter naturalmente o perfil de empreendedor, conquistar a confiança dos

\begin{tabular}{|ccccccccccc|}
\hline Participante & C-1 & C-2 & C-3 & C-4 & C-5 & C-6 & C-7 & C-8 & C-9 & C-10 \\
\hline E1 & 17 & 17 & 23 & 18 & 21 & 23 & 19 & 18 & 16 & 23 \\
E2 & 19 & 16 & 17 & 17 & 16 & 19 & 19 & 13 & 18 & 19 \\
E3 & 19 & 18 & 23 & 21 & 23 & 18 & 20 & 17 & 17 & 24 \\
E4 & 16 & 16 & 20 & 19 & 21 & 20 & 17 & 18 & 18 & 22 \\
E5 & 21 & 18 & 23 & 21 & 22 & 25 & 23 & 17 & 19 & 19 \\
E6 & 19 & 19 & 21 & 16 & 21 & 21 & 15 & 17 & 19 & 18 \\
E7 & 21 & 16 & 23 & 21 & 17 & 19 & 19 & 16 & 15 & 23 \\
E8 & 19 & 17 & 23 & 21 & 18 & 22 & 21 & 22 & 21 & 21 \\
E9 & 17 & 18 & 19 & 16 & 19 & 19 & 16 & 14 & 15 & 17 \\
E10 & 17 & 18 & 23 & 18 & 21 & 22 & 15 & 17 & 17 & 19 \\
\hline
\end{tabular}

Nota: C-1: Busca de oportunidade e iniciativa; C-2: Persistência; C-3: Comprometimento; C-4: Exigência de qualidade e eficiência; C-5: Correr riscos; C-6: Estabelecimento de metas; C-7: Busca de informações; C-8: Planejamento e monitoramento sistemático; C-9: persuasão e rede de contatos; C-10: Independência e autoconfiança.

FIGURA 2: Pontuação dos enfermeiros estudados em cada característica comportamental empreendedora. Município de médio porte do Centro-Oeste Mineiro, Julho a setembro de 2015. 
clientes e cautela buscando minimizar os riscos diante do desafio de empreender.

Você não pode ser medroso demais e você não pode ser corajoso demais. Se você tiver medo, não vai acontecer. Então, se você for corajoso demais, [... ], na maioria das vezes sua chance de margem de erro em seu negócio, pode custar seu negócio. [...] Então uma das primeiras coisas que eu faço, eu estou dentro da sua casa como prestador, mas eu estou aqui para você contar o que você precisa, então essa confiança que a pessoa tem em você é muito importante. (E1)

Outra característica reconhecida foi a capacidade de articulação entre o conhecimento técnico/científico:

E aí a coisa [empresa] foi crescendo, foi quando eu me tornei uma empreendedora, porque a coisa cresceu muito e eu comecei a estudar mais, vamos estudar mais. (E10) nidade.

E a identificação de uma necessidade/oportu-

Há 10 anos eu entendi a pirâmide em relação à idade da população brasileira, a realidade, [...] que o foco, nos próximos 10 anos, seria a população idosa. Aí eu falei, eu sei fazer é isso, eu vou ter campo. (E1)

As dificuldades para o empreendedorismo em enfermagem foram destacadas pelos participantes. Reconheceu-se inicialmente a multiplicidade de funções no empreendimento como uma dificuldade a ser superada:

Eu faço só a parte administrativa, mais $R H$ [...] faço treinamento para enfermeiras [...], a parte de segurança do trabalho também sou eu quem fico à frente. (E9). Outro entrevistado destaca: Hoje eu sou enfermeiro, sou responsável técnico pela empresa, sou administrador da empresa e eu trabalho na parte de urgência e emergência, faço transporte aéreo, faço transporte terrestre [...] é muita coisa para uma pessoa só! (E6)

Reconheceu-se também como dificuldades o desconhecimento de lei e a burocracia para implementação do empreendimento:

[...] a gente não conhecia todas as leis e tudo, aí, depois que você começa a mexer, você vê a burocracia que é. (E5)

A falta de fiscalização e o desconhecimento dos órgãos responsáveis sobre o empreendimento proposto também foi reconhecida como dificuldades enfrentadas pelos enfermeiros.

Ninguém te fiscaliza, ninguém te cobra, nem eticamente, nem judicialmente [...] E quando eu fui abrir, a própria vigilância sanitária desconhecia o tipo de serviço, as pessoas que estavam na vigilância nunca tinham vivenciado isso, então é muito complicado, você chega num órgão que vai te avaliar, ele não tem referência do que é certo, do que é errado. (E1)

A credibilidade diante da clientela pelo fato de ser enfermeiro foi outra dificuldade vivenciada:

Porque você tem um conhecimento, sou enfermeiro e muitas vezes as pessoas não acreditam no seu conhecimento. (E3)
Além disso, há dificuldade em se manter no mercado, em conquistar a confiança das pessoas. Nem sabem que o enfermeiro tem conhecimento para realizar aquele serviço, difícil! (E7).

Também foi destacada a indisponibilidade inicial de recursos financeiros para iniciar o empreendimento:

O mais difícil é o dinheiro para começar, ainda mais com essa crise que nós estamos passando. (E7)

Outra dificuldade reconhecida foi à concorrência desleal no mercado. A queixa é de que alguns serviços são oferecidos de forma amadora e com um valor reduzido. Essa situação acaba repercutindo negativamente na imagem do profissional e em sua desvalorização.

Hoje, a maior situação que incomoda seria o amadorismo e essa concorrência só prejudica. Porque a partir do momento que a pessoa torna um serviço mais barato isso vai refletir no profissional, desvaloriza a profissão da gente, também, desvaloriza, assim, a imagem em geral [...] os colegas não visualizam isso, eles brigam pelo paciente. (E1)

Existe a competitividade. Existe outro home care na cidade, então em todas as áreas tem competição. Às vezes, a família liga para mim querendo um orçamento, mas liga também para o home care do colega querendo um orçamento. (E4)

Além das dificuldades reconhecidas pelos enfermeiros, também emergiram relatos que destacaram a satisfação sobre sua atividade empreendedora e metas futuras. Mesmo com todas as dificuldades apresentadas pelos enfermeiros, a satisfação pessoal e profissional foi manifestada em relação ao seu empreendimento:

Eu falo-é ótimo, muito bom para mim, só tenho a agradecer, mudou muito a minha vida, e assim, mesmo que eu parasse hoje com esse serviço, já me deu muitas coisas boas. (E1)

O reconhecimento do trabalho também é manifestado: 'Bastante feliz porque eu sinto que hoje eu sou uma enfermeira útil, uma enfermeira que tem um diferencial, sou reconhecida por isso [...] '.(E3)

Constatou-se que os enfermeiros já projetavam suas metas futuras para o empreendimento, planejavam sua expansão:

Até mesmo as ampliações do alcance além dos limites do município são planejadas: então o foco para os próximos dois anos é expansão na média de $200 \mathrm{~km}$, que é onde a gente consegue ter um acesso de gestão. (E1)

Outros já destacam a ampliação estrutural do negócio: 'um espaço bem maior que esse, se Deus quiser um espaço três vezes maior que esse, em breve'. (E9)

\section{DISCUSSÃo}

Os enfermeiros em estudo, em sua maioria, possuem empreendimentos registrados e com alta lucratividade quando comparados aos enfermeiros que atuam no mercado de trabalho tradicional, predominando a assistência domiciliar e assistência a idosos em instituições de longa permanência. Estas constatações remetem às possibilidades inovadoras de atuação em variados nichos de trabalho proporcionado 
pelo empreendedorismo de negócios no contexto da enfermagem. Esse achado demonstra o conceito do ser empreendedor evidenciado por Schumpeter, como aquele com capacidade de criação de novos e/ou renovação de processos tradicionais ${ }^{2}$. Além disso, reforça a importância do enfermeiro em atuar num mercado cada vez mais demandado, o da assistência domiciliar e também a assistência à população idosa ${ }^{20}$.

Dentre os enfermeiros em estudo, nota-se que há aqueles que não possuem nenhum tipo de especialização e outros com várias especializações. Entretanto, a maioria dessas especializações não tem relação com o tipo de empreendimento oferecido, contribuindo pouco para a execução de suas atividades empreendedoras. Ou seja, apesar da ausência de especialização ou especialização inadequada ao empreendimento proposto, os enfermeiros têm se aventurado em negócios que exigem certo nível de conhecimento. Sabe-se que no meio empresarial, um aperfeiçoamento profissional é fundamental para a abertura de novos caminhos e alternativas de trabalho, dessa forma a aquisição de novos conhecimentos voltados para o próprio negócio favorece a obtenção do sucesso ${ }^{21}$. Para o indivíduo ser bem-sucedido em seu empreendimento, deve-se trabalhar o intelectual a fim de se ampliar aquilo que a mente humana produzira de criativo ${ }^{2}$.

Em relação às $\mathrm{CCE}$, verificou-se que a busca de informações, planejamento e monitoramento sistemático e persuasão e rede de contato devem ser potencializadas entre os enfermeiros pesquisados. 0 empreendedorismo de negócios exige um planejamento sistemático embasado em informações fidedignas, sendo um diferencial competitivo e base para o início do empreendimento ${ }^{22}$. No que tange à persuasão $e$ rede de contatos, são CCE que potencializam o empreendimento, a partir do convencimento da necessidade e qualidade daquele serviço, além de estabelecer uma rede de relacionamentos para disseminar a visibilidade do empreendimento ${ }^{23}$.

Apesar das universidades serem consideradas instituições importantes na formação de futuros empreendedores ${ }^{24}$, a maioria dos enfermeiros entrevistados não as reconheceu como incentivadoras ao empreendedorismo, salientando uma lacuna na graduação em enfermagem quando se trata do incentivo ao empreendedorismo.

Dentre as motivações iniciais para abertura de seus empreendimentos, os enfermeiros destacaram a possibilidade de ter o seu próprio negócio e a possibilidade de lucratividade e independência. A motivação ao empreendedorismo muitas vezes se dá pela interação de diversos fatores. Para muitos indivíduos a motivação ao empreendedorismo se dá pela identificação de uma oportunidade ou necessidade, para outros, pela possibilidade de adquirirem autonomia ${ }^{25}$.

Em relação aos fatores que facilitaram o desenvolvimento de seus negócios, a família foi reconhecida como fundamental na decisão de empreender, corroborando a constatação de que é importante envolver a família na rede de apoio ao empreendedor ${ }^{26}$.

As vivências e conhecimentos prévios acerca do mercado potencializaram a decisão de empreender. 0 indivíduo com experiência prévia tem maior capacidade de manter a motivação inicial e de enfrentar os desafios e dificuldades, pois esses indivíduos possuem maior conhecimento das demandas do mercado ${ }^{27}$.

Observou-se também que algumas características relacionadas à personalidade dos enfermeiros potencializaram o empreendedorismo de negócios. Esses achados endossam o fato de que o diferencial de um profissional não está exclusivamente em suas habilidades, currículo, formação ou experiência, mas também no seu comportamento, percepção de mundo e na capacidade de inovar, criar e se reinventar ${ }^{28}$. O sucesso do empreendedor depende de sua intuição, da sua capacidade de ver as coisas de uma maneira diferenciada e de se perceber o essencial e deixar de lado a superficialidade do negócio ${ }^{2}$

Em relação às dificuldades enfrentadas para empreender, a multiplicidade de funções foi destacada gerando sobrecarga de trabalho, mostrando fragilidades na estruturação do empreendimento e potencializando influências negativas a sobrevivência e competitividade do negócio.

Outra dificuldade verificada foi o desconhecimento da legislação necessária para regulamentação do empreendimento. O Brasil está avançando lentamente comparado a outros países que buscam a inovação e o principal problema identificado não é a ausência de recursos, mas sim a falta de acesso a informações por parte dos empreendedores ${ }^{29}$.

Também foi apontada a dificuldade financeira como um grande desafio, algo que precisa ser considerado, pois a sobrevivência e crescimento no mercado são consequências de uma infraestrutura financiada adequadamente, o que é, portanto, essencial para uma prestação de cuidados de alta qualidade ${ }^{30}$.

A concorrência desleal, atrelada à falta de credibilidade e desconhecimento da população sobre as possibilidades de atuação do enfermeiro, também foi apontada como dificuldades, que influenciam negativamente na atividade empreendedora proposta ${ }^{31}$.

Outras dificuldades relatadas (excesso de burocracia, ausência de fiscalização e desconhecimento dos órgãos competentes) demonstram fragilidades na regulação do mercado pelas instâncias responsáveis. Quem deveria facilitar a abertura do empreendimento e fiscalizá-lo pode não estar preparado para tal atribuição. Isso leva ao debate da necessidade de avanços no setor de abertura e fiscalização. Historicamente, tem havido desafios e barreiras para iniciativas de empreendedorismo por enfermeiros ${ }^{32}$. Entretanto, apesar das dificuldades apresentadas, os enfermeiros alegaram 
satisfação pessoal e profissional a partir de seus empreendimentos, bem como já vislumbram possibilidades de expansões e metas futuras ${ }^{33}$.

Admite-se impossibilidade de generalizações por se tratar de estudo de caso, mas evidencia-se a sua importância enquanto norteador de outros trabalhos que aprofundem a temática do empreendedorismo de negócios no contexto da enfermagem. É preciso compreender o cotidiano de trabalho desses empreendedores, bem como são necessários estudos que elucidem possibilidades de inserção do empreendedorismo de negócios no contexto da formação em enfermagem.

\section{CONCLUSÃo}

O empreendedorismo de negócios neste estudo foi caracterizado pela articulação entre a formação, as características pessoais, reconhecimento de uma oportunidade no mercado e experiências adquiridas pelos enfermeiros investigados. Constatou-se que os enfermeiros necessitam fortalecer algumas características comportamentais como a busca de informações, planejamento e monitoramento sistemático e persuasão e rede de contatos.

Dentre as motivações iniciais destacou-se a possibilidade de lucratividade no mercado. Os participantes possuem empreendimentos registrados predominando a assistência domiciliar e instituições de longa permanência. Para empreender, os participantes reconheceram e enfrentaram desafios e dificuldades para iniciar e manter seus negócios e apesar das dificuldades eles, reconhecem a satisfação em seus empreendimentos e já vislumbram metas futuras.

As limitações encontradas no presente estudo estão relacionadas à falta de pesquisas nacionais e internacionais com o mesmo objetivo e população alvo. Também se relaciona a questão de muitos profissionais não serem do município em estudo.

\section{REFERÊNCIAS}

1. Morais JA, Háddad MCL, Rossaneis MA, Silva LGC. Práticas de enfermagem empreendedoras e autônomas. Cogitare enferm. [Online]. 2013 [acesso em 21 nov 2017]; 18(4): 695-701. Disponível em: http://revistas.ufpr.br/cogitare/article/view/46422/27872 2. Schumpeter JA. Capitalismo, socialismo e democracia. Rio de Janeiro: Fundo de Cultura; 1961.

3. Sousa ACS, Lima DBS, Alves FCG. Empreendedorismo: estudo de caso grupo Stick Fran. Revista Fórum de Administração [Online]. 2013 [acesso em 21 nov 2017]; 6(1)1-18. Disponível em: http://periodicos. unifacef.com.br/index.php/forumadm/article/view/948/757

4. Jahani S, Abedi H, Elahi N, Fallahi KM. Iranian entrepreneur nurses' perceived barriers to entrepreneurship: a qualitative study. Iran. J. Nurs. Midwifery Res. [Online]. 2016 [cited 2017 Nov 21]; 21(1):45-53. Available from: https://www.ncbi.nlm.nih.gov/pmc/ articles/PMC4776560

5. Rowe MA. Nurse entrepreneurs, arise!: improving lives of older adults by bringing your ideas to market. J. Gerontol. Nurs. 2013 [cited 2017 Nov 21]; 39(10): 16-21. Available from: https://www. ncbi.nlm.nih.gov/pubmed/24015886
6. Silva ACP, Valente GLC, Valente GSC. O empreendedorismo como uma ferramenta para atuação do enfermeiro. Rev. enferm. UFPE on line 2017 [acesso em 21 mar 2018]; 11(4): 1595-1602. Disponível em: https://periodicos.ufpe.br/revistas/revistaenfermagem/article/viewFile/15227/17992

7. Dehghanzadeh MR, Golrasteh K, Masoumeh B, Ensich A, Mohamad RS, HosseinN. Entrepreneurship psychological characteristics of nurses. Acta Med Iran [Online]. 2016 [cited 2017 Nov 21]; 54(9): 595-9. Available from: http://acta.tums.ac.ir/index. php/acta/article/viewFile/5162/4837

8. Backes DS, Ilha S, Weissheimer AS, Halberstadt BMK, Megier $E R$, Machado R. Socially entrepreneurial activities in nursing: Contributions to health/healthy living. Esc. Anna Nery Rev Enferm. 2016 [cited 2017 Set 21]; 20(1):77-82. Available from: http:// www.scielo.br/pdf/ean/v20n1/en_1414-8145-ean-20-01-0077 9. Morais JA, Haddad MCL, Rossaneis MA, Silva LGC. Práticas de enfermagem empreendedoras e autônomas. Cogitare enferm. [Online]. 2013 [acesso em 21 mar 2018]; 8(4):695-701. Disponível em: http://ojs.c3sl.ufpr.br/ojs/index.php/cogitare/article/ view/34922/21676.

10. Dolabela F. Oficina do empreendedor: a metodologia de ensino que ajuda a transformar conhecimento em riqueza. São Paulo. ed. Cultura editores associados, 1999.

11. Hisrich RD, Peters MP, Shepherd DA. Empreendedorismo, 9a ed. Porto Alegre, (RS): AMGH Editora LTDA ; 2014.

12. Teixeira EVEG, Fernandes JD, Sordi MRL. Trajetória e tendências dos cursos de enfermagem no Brasil. Rev. bras. enferm. [Online]. 2006 [acesso em 21 mar 2018]; 59(4): 479-87. Disponível em: http://www.scielo.br/pdf/reben/v59n4/a02v59n4.pdf.

13. Camelo SHH, Soares IM, Chaves LDP, Rocha RLF, Silva VLS. Enfermeiros gerentes de um hospital de ensino: formação profissional, responsabilidades e desafios. Rev. enferm. UERJ. 2016 [acesso em: 21 mar 2018]; 24(3):e11637. Disponível em: https:// www.e-publicacoes.uerj.br/index.php/enfermagemuerj/article/ view/11637/19389

14. Tossin CB, Silva LGC, Rossaneis MA, Haddad MCFL. Perfil empreendedor de docentes do curso de enfermagem de uma universidade pública. Rev. enferm. UERJ, Rio de Janeiro [Online]. 2017 [Acesso em: 21 Nov 2018]; 25:e 22233. Disponível em: https://www.e-publicacoes.uerj.br/index.php/enfermagemuerj/ article/view/22233/22015

15. Yin RK. Estudo de caso: planejamento e métodos. 5 a ed. Porto Alegre (RS): Bookman; 2015.

16. Minayo MCS. O desafio do conhecimento: pesquisa qualitativa em saúde. 13a ed. São Paulo: Hucitec; 2013.

17. Vinuto JA. Amostragem em bola de neve na pesquisa qualitativa: um debate em aberto. Temáticas, Campinas [Online]. 2014 [acesso em 21 mai 2017]; 22(44): 203-20. Disponível em: http://www.ifch.unicamp.br/ojs/index.php/tematicas/article/ view/2144/1637

18. Bardin L. Análise de conteúdo. São Paulo: Edições 70ą; 2015. 19. Werlang NB, Fonseca J. Competências empreendedoras e startups: um estudo com gestores de empresas embrionárias catarinenses. Revista Eletrônica de administração e turismo [Online]. 2016 [acesso em 28 ago 2017]; 8(4): 851-69. Disponível em: https://periodicos.ufpel.edu.br/ojs2/index.php/AT/article/ view/6554/5672

20. Hermann AP, Nascimento JD, Lacerda MR. Specific characteristics of home healthcare and their approaches in nursing education. REME rev. min. enferm.2014 [cited 2017 Sep 21]; 18(3): 545-50. Available from: http://www.reme.org.br/artigo/detalhes/945 21. Barros Neto JM, Anjos EA, Silva SEV, Tavares CM, Pedro ANC. The formation of the professional nurse and the labor market today. Revista Eletrônica Gestão \& Saúde [Online]. 2014 [cited 2017 Sep 30]; 5(1): 176-93. Available from: http://www.repositorio.ufc. br/bitstream/riufc/9269/1/2014_art_cmtavares.pdf

22. Ferreira FLA, Gimenez FAP, Augusto POM. Empreendedorismo e o processo de criação de uma nova organização. Revista de Em- 
preendedorismo e Gestão de Pequenas Empresas [Online]. 2014 [acesso em 20 ago 2017]; 3(2):70-93. Disponível em: http://www. regepe.org.br/index.php/regepe/article/view/regepe32128/87 23. McClelland, D. C. The achieving society. New York: D. Van Nostrand Company; 1961

24. Copelli FHS, Santos JLG, Erdmann AL. Entrepreneurship in nursing public university management. J. Nurs. UFPE on line. 2016 [cited 2017 Sept 20]; 10(Suppl. 1):366-70. Available from: https:// www.researchgate.net/profile/Jose_Guedes_Dos_Santos2/publication/291167215_Entrepreneurship_in_nursing_public_university_management/links/569ed93208aee4d26ad055a8.pdf 25. Vale GMV, Corrêa VS, Reis RF. Motivations for entrepreneurship: necessity versus opportunity? Rev. Adm. Contemp. 2014 [cited 2017 Sep 20]; 18(3):311-27. Available from: http://www. scielo.br/pdf/rac/v18n3/v18n3a05.pdf

26. Alperstedt GD, Ferreira JB, Serafim MC. Empreendedorismo feminino: dificuldades relatadas em histórias de vida. Revista de Ciências da Administração [Online]; 2014 [acesso em 20 set 2017]; 16(40) 221-34. Disponível em: http://www.redalyc.org/ pdf/2735/273532832015.pdf

27. Reali AMR, Tancredi RMSP, Mizukami MGN.Comunidade de aprendizagem profissional: tensões nos processos de desenvolvimento profissional de mentoras. Educação (Porto Alegre) [Online]. 2016 [acesso em 15 set 2017]; 39(1): 121-32. Disponível em http://revistaseletronicas.pucrs.br/ojs/index.php/faced/article/ view/14500/14583.

28. Ferreira FLA, Gimenez FAP, Augusto POM. Empreendedorismo e o processo de criação de uma nova organização. Revista de Empreendedorismo e Gestão de Pequenas Empresas [Online]. 2014 [acesso em 16 set 2017]; 3(2): 70-93. Disponível em: http:// www.regepe.org.br/regepe/article/view/128

29. Conselho Nacional de Educação (Br) CNE/CES no 03 de 07 de Novembro de 2001: Diretrizes Curriculares Nacionais do Curso de Graduação em Enfermagem. Brasília (DF). CNE; 2001.

30. Wilson A, Whitaker N, Whitford D. Rising to the challenge of health care reform with entrepreneurial and intrapreneurial nursing initiatives. Online J. Issues Nurs. [Online]. 2012 [cited 2017 Sept 16]; 17(2) :5. Available from: https://www.ncbi.nlm. nih.gov/pubmed/22686113.

31. Avila LI, Silveira RS, Lunardi VL, Fernandes GFM, Mancia JR, Silveira JT. Implications of the visibility of professional nursing practices. Rev. gaúch. enferm. 2013 [cited 20 Sep. 2017]; 34(3): 102-9. Available from: http://www.scielo.br/scielo.php?script=sci_artte xt\&pid=S198314472013000300013

32. Cadmus E, Johansen ML, Zimmer PA, Knowlton DL. Entrepreneurship: assessing the readiness of the New Jersey APN workforce. Nurs. Adm. Q. [Online]. 2017 [cited 2018 Jan 06]; 41(1):48-55. Available from: https://www.ncbi.nlm.nih.gov/ pubmed/27918404.

33. Dehghanzadeh MR, Kholasehzadeh G, Birjandi M, Antikchi1 E, Sobhan MR, Neamatzadeh H. Entrepreneurship psychological characteristics of nurses. Acta Medica Iranica [Online]. 2016 [cited 2018 Nov 21]; 54(9): 596-9. Available from: http://acta.tums.ac.ir/ index.php/acta/article/view/5162/4837 